\title{
Operant serial feature-positive conditional discrimination with composite features and different topography responses
}

\author{
J.L.O. Bueno and A.A. Scaduto
}

Setor de Psicobiologia, Departamento de Psicologia e Educação, Faculdade de Filosofia, Ciências e Letras de Ribeirão Preto, Universidade de São Paulo, Ribeirão Preto, SP, Brasil

Correspondence to: J.L.O. Bueno, Setor de Psicobiologia, Departamento de Psicologia e Educação, FFCLRP, USP, 14049-900 Ribeirão Preto, SP, Brasil

E-mail: jldobuen@ffclrp.usp.br

In a serial feature-positive conditional discrimination procedure the properties of a target stimulus A are defined by the presence or not of a feature stimulus X preceding it. In the present experiment, composite features preceded targets associated with two different topography operant responses (right and left bar pressing); matching and non-matching-to-sample arrangements were also used. Five water-deprived Wistar rats were trained in 6 different trials: $X-R \rightarrow A r$ and $X-L \rightarrow A l$, in which $X$ and $A$ were same modality visual stimuli and the reinforcement was contingent to pressing either the right ( $\mathrm{r}$ ) or left (I) bar that had the light on during the feature (matching-to-sample); $\mathrm{Y}-\mathrm{R} \rightarrow \mathrm{BI}$ and $\mathrm{Y}-\mathrm{L} \rightarrow \mathrm{Br}$, in which $\mathrm{Y}$ and $\mathrm{B}$ were same modality auditory stimuli and the reinforcement was contingent to pressing the bar that had the light off during the feature (non-matching-to-sample); A- and Balone. After 100 training sessions, the animals were submitted to transfer tests with the targets used plus a new one (auditory click). Average percentages of stimuli with a response were measured. Acquisition occurred completely only for $\mathrm{Y}-\mathrm{L} \rightarrow \mathrm{Br}+$; however, complex associations were established along training. Transfer was not complete during the tests since concurrent effects of extinction and response generalization also occurred. Results suggest the use of both simple conditioning and configurational strategies, favoring the most recent theories of conditional discrimination learning. The implications of the use of complex arrangements for discussing these theories are considered.

Key words: Conditional discrimination; Occasion setting; Non-matching-to-sample/matching-to-sample; Operant; Rats

J.L.O. Bueno was the recipient of a CNPq Productivity Scholarship (\#304988/2005-7). Research supported by a CNPq research grant (\#475490-2006-1).

Received June 21, 2007. Accepted December 4, 2007

\section{Introduction}

In a Pavlovian feature-positive (FP) conditional discrimination procedure (XA+; $A-)$, a conditioned stimulus $A$, called target, is followed by reinforcement if preceded by an $\mathrm{X}$ stimulus, called feature, and not reinforced if presented alone; this procedure was first described by Jenkins and Sainsbury (1).

Different models have been proposed to elucidate the processes occurring in conditional discrimination learning. According to Rescorla (2), such learning would be established through a simple feature-reinforcement association; $X$ acquires the ability to elicit conditioned responses (CRs) during the presentation of $A$, which in turn has inhibitory properties when presented alone. Holland (3) proposed an occasion-setting hypothesis; a CR is generated by X's activation of A-unconditioned stimulus representation. It was observed that, in a Pavlovian serial FP conditional discrimination $(X \rightarrow A ; A+)$, the feature sets the occasion for a target-reinforcement relation (4). Another hypothesis (57) suggests that animals solve conditional discriminations by a configurational association of the feature-target compound with the reinforcement, that is, although feature and target have different information related to reinforcement separately, both would be considered as a single stimulus.

In order to evaluate which types of associations are 
established along conditional discrimination procedures, transfer tests can be used. Considering the arrangement of feature and target, conditional discriminations can be either serial (in which composite feature-target trials are presented serially, with a gap between them, i.e., $X \rightarrow A$, or without a gap, i.e., X-A) or simultaneous ones, where composite trials are presented at the same time, XA. Ross and Holland (4) proposed that simultaneous conditional discriminations are more likely to elicit primary associations between feature and reinforcement stimuli, while serial ones can elicit occasion-setting associations. Transfer tests consist of the presentation of trials in which the feature precedes either different targets, which the subjects were not trained with, or other stimuli, which had not participated in the discrimination training. The transfer of feature properties to another target stimulus is observed in simultaneous conditional discriminations, but not in serial ones. The properties of the feature can also be tested by observing the topography of the response in Pavlovian procedures (4) and by counterconditioning of the feature stimulus trials (3).

The mechanisms involved in conditional discrimination learning have also been studied in operant conditioning procedures, in which there is an operant response between target and reinforcement. Holland (8) examined transfer of stimulus control after discrete-trial operant serial FP discrimination ( $X-A+/ A-)$ training in rats. The results showed the ability of $X$ features to facilitate responding to a subsequent target cue when the transfer target had been presented during training as the target in another serial FP discrimination, even if that target controlled a different operant than controlled by the original $A$ target. Transfer to a separately trained and extinguished target was smaller and occurred only if the original and transfer target controlled the same operant. The occasionsetting interpretation supposes that the features have the ability to act on both target-reinforcer and response-reinforcer associations subsumed by the four-term contingencies (9).

Holland (8) and Goddard and Holland (10) have suggested that the feature acted on the operant responsereinforcement relation; the stimulus modality could have been one of the possible determinants of the performance observed during transfer tests. The effects of stimulus modality were also observed in serial Pavlovian FPs; Ross and Holland (4) observed different CRs to targets of different modalities (that is, rearing CRs during panel light $(P)$ and head-jerk CRs during tone $(\mathrm{T})$ ).

Although similarities have been observed in both Pavlovian and operant procedures, the relations among the events differ between these experimental designs. Rela- tions among feature, target and reinforcement are involved in Pavlovian conditioning procedures. In operant conditioning procedures, the presence of the operant response between target and reinforcement can set a different feature control compared to Pavlovian conditioning procedures (11). The presence of an operant CR can add more complex properties to the target, as it can indicate not only reinforcement, but also a response-reinforcement relation; thus, a target can also acquire the same properties of a feature, that is, as an occasion setter (3).

In order to study the learning mechanisms involved in conditional discrimination procedures with operant responses, Caserta-Gon (11) used two topographies of the same response in rats: complete left or right rotation around their own axis. The use of similar operant responses would provide an analysis of the processes underlying different types of conditional discriminations by observing the effects of their representations in acquisition and transfer. Same-modality features and targets were used in a serial FP conditional discrimination for the right-topography response ( $\mathrm{P} \rightarrow \mathrm{Tr}+$; $\mathrm{T}-$ ), and in a serial feature-negative conditional discrimination for the left-topography response $(\mathrm{H} \rightarrow \mathrm{R}-; \mathrm{RI}+$ ), with $\mathrm{P}$ and $\mathrm{H}$ being visual stimuli (panel and house lights, respectively) and $T$ and $R$ being auditory stimuli (tone and white noise, respectively). The results showed acquisition of the task, but did not indicate transfer of the properties of both features (positive and negative) to targets that were part of the training. However, FP transfer to a new stimulus (click) was observed. These results may be explained as a generalization of same-modality stimuli (visual features and auditory targets). However, CasertaGon (11) also suggested that the lack of transfer indicates that the animals used an occasion-setting strategy, which explains the data pattern obtained in transfer tests - a specific association of the feature with the target-reinforcement relation. When there was no previous association between target and reinforcement, as in the case of the transfer test to a new stimulus, the primary association between feature and reinforcement prevailed and the FP properties were transferred to this new target stimulus. Animals can be controlled by different types of associations, primary and conditional, in the same procedure, pointing out the interaction of respondent processes (primary associations) and S-(R-reinforcement) conditional operant relations (10).

Bueno and Croisfelts (12) also used serial FP and feature-negative conditional discriminations, with different topographies of the same response, right- or left-lever pressing (as indicated below, $r$ and I, respectively). In order to analyze how stimulus modality would affect acquisition, different modality features and targets were used. Auditory 
$\mathrm{T}$ and $\mathrm{W}$ (white noise) were used in FP trials $(\mathrm{W} \rightarrow \mathrm{Tr}+, \mathrm{T}-)$ and visual $P$ and $H$ were used in the feature-negative conditional discrimination pattern $(\mathrm{P} \rightarrow \mathrm{H}-, \mathrm{HI}+)$. The data showed acquisition of the task; during transfer tests, feature-negative $P$ transfer was observed to $T$, preceded during training by FP W. Transfer of FP W properties was also observed to target $\mathrm{H}$. However, as right- and leftresponding rates had similar distributions, the responding topography suggests both feature and target control. This result did not allow a definition of which strategy was used by the animals (simple or occasion-setting associations).

Considering that more complex processes than the use of only one strategy may be related to conditional discrimination acquisition (11) and that the stimulus modality acts on acquisition and transfer $(8,12)$, the objective of the present study was to analyze the hierarchical structure of learning in an operant serial FP conditional discrimination. In order to do so, we used composite features that could acquire different properties depending on their first element, in two serial FP conditional discrimination procedure arrangements (non-matching-to-sample, NMTS, and matching-to-sample, MTS), using an operant response with two topographies. With this procedure, an evaluation of variables such as stimulus modality and topography of the response can be studied in terms of their relevance for stimulus representation processing and learning.

This study allows an evaluation of the ability of animals to discriminate events at the moment when reinforcement probability is the highest (targets preceded by features), besides discriminating which response is reinforced (rightor left-lever pressing), according to the schedule signaled by the bar lights. The use of transfer tests can allow an evaluation of which associations were established among composite features, targets, responses, and reinforcement, elucidating which learning mechanisms were relevant to acquisition for this type of conditional discrimination.

\section{Subjects and Methods}

\section{Subjects}

The subjects were 9 experimentally naive male Wistar rats bred in the central colony room of the University of São Paulo. The rats were about 120 days old at the beginning of the experiment and were housed individually in cages in the laboratory colony room with lights on from 6:00 am to 8:00 pm. When the animals reached a stable weight, they were water-deprived until they reached $80 \%$ of their predeprivation weights. The animals were maintained at $80 \%$ of their ad libitum body weight throughout the experiment by restricting their access to water, which was available for about 10 min a day in their individual cages. Food, however, was available at all times.

Along the experiment, 4 animals were excluded after an individual analysis. One of them died before the end of the experiment, and the other 3 showed no acquisition of stimulus-responding training events (see details in Procedure below). For this study, only animals that emitted responses at both topographies were considered. Thus, 5 animals were used as subjects for the data presented here.

\section{Apparatus}

The apparatus used consisted of four identical two-bar Skinner boxes (Lafayette model), measuring $20 \times 20 \times 23$ $\mathrm{cm}$, with stainless steel lateral walls and acrylic roof, front and back walls. The boxes were adapted to wooden isolation chambers, with a glass window in the center of each door. All boxes had a 2-cm diameter water holder on the left lateral wall $1.5 \mathrm{~cm}$ from the floor, halfway to the door and the back wall of the box. A red-colored, 120-V and 5 -W lamp, installed $1 \mathrm{~cm}$ from the roof of all isolation chambers, dimly illuminated the boxes during the sessions. A white-colored, 5-W lamp (house light, $H$ ), installed $1 \mathrm{~cm}$ from the roof of the chamber, was programmed to light in flashes. Two white-colored 40-mA lamps (bar lights, $\mathrm{RB}$ for the right-bar light, and LB for the left-bar light) were placed above the center of each of the two bars, $14 \mathrm{~cm}$ above the water holder. Another white-colored 40-mA lamp (panel light, $P$ ) was placed $23 \mathrm{~cm}$ from the floor, in the middle of the space between the two bars. All house, bar and panel lights were turned off, being turned on by an interface only during training trials. The auditory cues were a $100-\mathrm{Hz}, 30-\mathrm{dB}$ tone $(\mathrm{T})$, produced by an RFM audio generator (Departamento de Fisiologia, Faculdade de Medicina de Ribeirão Preto), a 68-dB white noise (W) produced by a noise generator model 901B (Grasson-Stadler, USA) and the reproduction of the voice number \#1 (tambourine) of a Roland electronic drum, model TR-626 (USA), named Click (C). All the auditory cues were presented through four 20-W speakers installed in the isolation boxes.

The events presented in each session were controlled by an interface developed in our laboratory (13) linked to a Pentium $166 \mathrm{MHz}$ computer. The Contrexp software for experimental control of animal learning research (14) was used.

\section{Procedure}

All rats were submitted to operant response training sessions and then stimulus-related conditioning. First, they were submitted to a water holder training session with 10 trials that consisted of water delivery at the times the 
subjects got closer to the holder. Next, three shaping sessions were run in which the subjects had to press either a right or a left bar in order to obtain water reinforcement. Two hundred water-drop reinforcements were liberated in a response-alternating schedule from three same-bar responses on.

After this training the rats were submitted to four stimulus-responding training sessions where $\mathrm{T}$ and $\mathrm{H}$ were presented. In these training sessions, 20 trials were reinforced after either right ( $\mathrm{Tr}+; \mathrm{Hr}+)$ or left ( $\mathrm{TI}+; \mathrm{HI}+)$ bar pressing in a 1-min variable interval reinforcement schedule. In the first and second sessions, the stimuli were presented for $10 \mathrm{~s}$ and in the remaining sessions, they were presented for $5 \mathrm{~s}$. After this training, the animals were submitted to serial FP conditional discrimination training.

Serial feature-positive conditional discrimination training. The animals were submitted to 100 training sessions in which each of the 6 different trials described below were presented twice. Three types of trials were presented according to their reinforcement schedule.

Non-matching-to-sample trials. In W-LB $\rightarrow \mathrm{Tr}+$ trials, 5s W, followed by 5-s LB was presented to the subjects; after this composite feature, there was a 10-s time gap with no stimulus presentation $(\rightarrow)$. After this time gap, 5-s T was presented; a right bar-pressing response was reinforced once if emitted during the presentation of the target. In W$\mathrm{RB} \rightarrow \mathrm{TI}+$ trials, 5-s $\mathrm{W}$ was presented to the subjects, followed by 5-s RB; after this composite feature, there was a 10-s time gap with no stimulus presentation. After the gap, 5s T was presented; a left bar-pressing response was reinforced once if emitted during the presentation of the target.

Matching-to-sample trials. In $\mathrm{P}-\mathrm{RB} \rightarrow \mathrm{Hr}+$ trials, 5-s $\mathrm{P}$ followed by 5 -s RB was presented to the subjects; after this composite feature, there was a 10-s temporal gap. After this gap, 5-H was presented; a right bar-pressing response was reinforced once if emitted during the presentation of the target. In P-LB $\rightarrow \mathrm{HI}+$ trials, 5-s $\mathrm{P}$ followed by 5-s LB was presented to the subjects; after this composite feature, there was a 10-s time gap. After this gap, 5-s $\mathrm{H}$ was presented; a left bar-pressing response was reinforced once if emitted during the presentation of the target.

Non-reinforced trials. During $\mathrm{T}$ - and $\mathrm{H}$ - trials, 5-s T or 5$\mathrm{s} \mathrm{H}$ was presented to the subjects, with no water delivery regardless of responding.

In reinforced trials, only the first responses emitted during target presentation were reinforced; neither other bar-pressing responses after the first one during target presentation, nor responding after the target presentation were reinforced. Each session lasted $76 \mathrm{~min}$, with two presentations of each of the trials described above, randomized with an inter-trial interval (ITI) ranging from 4 to 9 $\min$ (average ITI = $6.5 \mathrm{~min}$ ).

Transfer tests. After the serial FP conditional discrimination training, subjects were submitted to sessions with the same duration, number of presented trials, duration of stimulus presentation, and ITI. Serial FP conditional discrimination training trials and new ones were presented to the subjects in order to test the properties acquired by the features. In transfer tests 1-4, the composite features preceded targets; the subjects had not been trained with in the last training. In transfer test 5 , the trials consisted of the composite features preceding a new stimulus (auditory click) in order to evaluate transfer of the properties to a stimulus that did not take part in the conditional discrimination. None of the trials were reinforced. Between transfer test sessions, the subjects were submitted to one serial FP conditional discrimination refresher session in order to avoid conditioning extinction.

Transfer test 1 . Two $\mathrm{W}-\mathrm{LB} \rightarrow \mathrm{T}-$ trials, two $\mathrm{W}-\mathrm{RB} \rightarrow \mathrm{T}-$ trials, two $\mathrm{W}-\mathrm{LB} \rightarrow \mathrm{H}$ - trials, two $\mathrm{W}-\mathrm{RB} \rightarrow \mathrm{H}$ - trials and also two $\mathrm{T}-$ and $\mathrm{H}$ - trials were presented to the subjects.

Transfer test 2. Two $\mathrm{P}-\mathrm{RB} \rightarrow \mathrm{H}-$ trials, two $\mathrm{P}-\mathrm{LB} \rightarrow \mathrm{H}-$ trials, two $\mathrm{P}-\mathrm{RB} \rightarrow \mathrm{T}-$ trials, two $\mathrm{P}-\mathrm{LB} \rightarrow \mathrm{T}-$ trials and also two $\mathrm{T}-$ and $\mathrm{H}$ - trials were presented to the subjects.

Transfer test 3. Two W-LB $\rightarrow$ T- trials, two $\mathrm{W}-\mathrm{RB} \rightarrow \mathrm{T}-$ trials, two $\mathrm{P}-\mathrm{RB} \rightarrow \mathrm{T}-$ trials, two $\mathrm{P}-\mathrm{LB} \rightarrow \mathrm{T}$ - trials and also two $\mathrm{T}-$ and $\mathrm{H}$ - trials were presented to the subjects.

Transfer test 4. Two $\mathrm{P}-\mathrm{RB} \rightarrow \mathrm{H}-$ trials, two $\mathrm{P}-\mathrm{LB} \rightarrow \mathrm{H}-$ trials, two $\mathrm{W}-\mathrm{LB} \rightarrow \mathrm{H}$ - trials, two $\mathrm{W}-\mathrm{RB} \rightarrow \mathrm{H}$ - trials and also two $\mathrm{T}-$ and $\mathrm{H}$ - trials were presented to the subjects.

Transfer test 5. Two W-LB $\rightarrow$ C- trials, two W-RB $\rightarrow \mathrm{C}-$ trials, two $\mathrm{P}-\mathrm{RB} \rightarrow \mathrm{C}$ - trials, two $\mathrm{P}-\mathrm{LB} \rightarrow \mathrm{C}$ - trials and also two $\mathrm{T}-$ and $\mathrm{H}$ - trials were presented to the subjects.

The complete experimental design is summarized in Table 1.

Data recoding and treatment. All responding emitted during the experiment was recorded by the CONTREXP software (14). Preference measures (S) during the stimulus-responding training sessions were calculated during ITIs, $T$ and $H$ using the equation $S=R /(R+L)$, where $S$ is the right-bar preference measure, $R$ is the right responding to the events, and $L$, the left responding. During serial FP conditional discrimination training, the average percentages of trials with responses were calculated for each 10session block. Percentages were measured during presentation of composite features, time gaps and targets. Responding during $\mathrm{W}$ in $\mathrm{W}-\mathrm{LB} \rightarrow \mathrm{Tr}+$ and $\mathrm{W}-\mathrm{RB} \rightarrow \mathrm{TI}+$ trials and during $\mathrm{P}$ in $\mathrm{P}-\mathrm{RB} \rightarrow \mathrm{Hr}+$ and $\mathrm{P}-\mathrm{LB} \rightarrow \mathrm{HI}+$ trials was calculated and is presented in the figures as a single measure in order to simplify data presentation. During transfer tests, average percentages of trials with responses were also calculated for composite feature elements, time 
gaps and target presentations.

Data were analyzed statistically by ANOVA and the post hoc Newman-Keuls test. The significance level adopted was $P=0.05$. Ethical standards regarding subjects' care were followed according to FFCLRP's Animal Ethics Committee (Resolution 196/96).

\section{Results}

The average group responding indicated no preference for any of the bars during the stimulus-responding training, in which reinforced target-alone trials ( $\mathrm{T}$ and $\mathrm{H})$ for right or left responding were presented to the subjects. The subjects emitted responses in about $50 \%$ of the trials presented on the right bar in the last training session: the preference measures (S) were 0.45 for ITI responding, (S) $=0.55$ during $\mathrm{T}$ presentations, and $(\mathrm{S})=0.40$ for $\mathrm{H}$ presentations.

\section{Conditional discrimination training}

Figures 1 and 2 show the average percentages of events with responding during the last 10 -session block of the serial FP conditional discrimination training. Only the first responses emitted were considered.

The results show that training produced different control of the reinforcement schedule under NMTS and MTS. During this training, the statistical effects of the reinforcement schedule (NMTS versus MTS, ANOVA $F(1,4)=$ 22.64007, $\mathrm{P}<0.01)$ and stimulus $(F(7,28)=37.55464, \mathrm{P}<$ $0.0025)$ were significant. Also, statistically significant interaction effects of topography of response versus reinforcement schedule $(F(1,4)=12.07807, \mathrm{P}<0.01)$, reinforcement schedule versus stimulus $(F(7,28)=5.98532, \mathrm{P}<$ 0.01 ) and an interaction among topography of response, reinforcement schedule and stimulus $(F(7,28)=2.43187$, $\mathrm{P}<0.05)$ were obtained.

Non-matching-to-sample trials. Figure 1 shows the performance of the subjects during NMTS trials. ANOVA showed statistically significant effects of topography of response $(F(1,4)=9.90431, P<0.03)$ and stimulus $(F(7,28)$ $=32.52515, \mathrm{P}<0.01)$. Post hoc comparisons showed that right-bar responding during $\mathrm{T}$ in $\mathrm{W}-\mathrm{LB} \rightarrow \mathrm{Tr}+$ and left-bar responding during $\mathrm{T}$ in $\mathrm{W}-\mathrm{RB} \rightarrow \mathrm{TI}+$ were higher than responding during $\mathrm{T}-$, suggesting $\mathrm{T}+/ \mathrm{T}-$ discrimination.

Analysis of topography of response effects confirmed the acquisition of $\mathrm{T}+/ \mathrm{T}$ - discrimination and right-bar responding discrimination in NMTS trials: right-bar responding was higher during gaps and reinforced targets than in target-alone trials (topography of response and stimulus effects (ANOVA): $F(1,4)=8.2997369, P<0.04$ and $F(4,16)$ $=71.46719, \mathrm{P}<0.01$, respectively). A post hoc compari- son showed that there was higher responding on the right than the left bar during $\mathrm{T}$ in $\mathrm{W}-\mathrm{LB} \rightarrow \mathrm{Tr}+$ trials, but no differential topography responding during $\mathrm{T}$ in $\mathrm{W}-\mathrm{RB} \rightarrow \mathrm{TI}+$ trials. Thus, an excitatory component for right-bar responding during targets preceded by composite features seems to have had an important effect on NMTS trials.

Table 1. Experimental design.

\section{Experimental procedure}

Magazine training

Bar-pressing training

Shaping session

CRF 200 alternate-responding training

Stimuli responding training

$\mathrm{Tr}+\mathrm{Tl}+\mathrm{Hr}+\mathrm{HI}+$

Serial feature-positive conditional

discrimination training
$\mathrm{W}-\mathrm{LB} \rightarrow \mathrm{Tr}+$
$\mathrm{P}-\mathrm{RB} \rightarrow \mathrm{Hr}+$
$\mathrm{W}-\mathrm{RB} \rightarrow \mathrm{TI}+$
$\mathrm{P}-\mathrm{LB} \rightarrow \mathrm{HI}+$

Transfer test 1:

$\mathrm{W}-\mathrm{LB} \rightarrow \mathrm{T}-$

$\mathrm{W}-\mathrm{LB} \rightarrow \mathrm{H}-$

$\mathrm{W}-\mathrm{RB} \rightarrow \mathrm{T}$

W-RB

Refresher session (serial feature-positive

conditional discrimination training)

$\begin{array}{lll}\mathrm{W}-\mathrm{LB} \rightarrow \mathrm{Tr}+ & \mathrm{W}-\mathrm{RB} \rightarrow \mathrm{Tl}+ & \mathrm{T}- \\ \mathrm{P}-\mathrm{RB} \rightarrow \mathrm{Hr}+ & \mathrm{P}-\mathrm{LB} \rightarrow \mathrm{HI}+ & \mathrm{H}-\end{array}$

Transfer test 2:

$\mathrm{P}-\mathrm{RB} \rightarrow \mathrm{H}-$

$\mathrm{P}-\mathrm{RB} \rightarrow \mathrm{T}-$

$$
\begin{aligned}
& \text { P-LB } \rightarrow \text { H- } \\
& \text { P-LB } \rightarrow \text { T- }
\end{aligned}
$$

Refresher session (serial feature-positive conditional discrimination training)

Transfer test 3:

$\mathrm{W}-\mathrm{LB} \rightarrow \mathrm{T}^{-} \quad \mathrm{W}-\mathrm{RB} \rightarrow \mathrm{T}_{-} \quad \mathrm{T}-$

$\mathrm{P}-\mathrm{RB} \rightarrow \mathrm{T}-\quad \mathrm{P}-\mathrm{LB} \rightarrow \mathrm{T}-\quad \mathrm{H}-$

Refresher session (serial feature-positive conditional discrimination training)

Transfer test 4: $\mathrm{P}-\mathrm{RB} \rightarrow \mathrm{H}-\quad \mathrm{P}-\mathrm{LB} \rightarrow \mathrm{H}-\quad \mathrm{H}-$ $\mathrm{W}-\mathrm{LB} \rightarrow \mathrm{H}-\quad \mathrm{W}-\mathrm{RB} \rightarrow \mathrm{H}-\quad \mathrm{T}-$

Refresher session (serial feature-positive conditional discrimination training)

Transfer test 5 :
W-LB $\rightarrow$ C-
$\mathrm{W}-\mathrm{RB} \rightarrow \mathrm{C}$
T-

$\mathrm{P}-\mathrm{RB} \rightarrow \mathrm{C}-\quad \mathrm{P}-\mathrm{LB} \rightarrow \mathrm{C}-\quad \mathrm{H}-$

CRF $200=$ continuous reinforcement schedule, delivered 200 times for pressing responses on right ( $r$ ) and left (I) bars; $T=5$-s tone presentation; $\mathrm{H}=5$-s house light presentation; $\mathrm{W}=5$-s white noise presentation; $P=5$-s panel light presentation; RB/LB $=5$-s right/left bar light presentation; hyphen in abbreviations $\mathrm{W}$ $\mathrm{RB} / \mathrm{LB}$ or P-RB/LB = followed by; +/- = reinforcement/non-reinforcement; $C=5$-s click presentation; $\rightarrow=10$-s temporal gap. 
Matching-to-sample trials. Figure 2 shows the performance of the subjects during MTS trials. A statistically significant effect of stimulus $(F(7,28)=26.625, P<0.01)$ was obtained. The post hoc test revealed acquisition of $\mathrm{H}+/ \mathrm{H}$ - discrimination, with a statistically significant higher right-bar responding during $\mathrm{H}+$ than during $\mathrm{H}$ - in $\mathrm{P}-\mathrm{RB} \rightarrow \mathrm{Hr}+$ trials and higher left-bar responding during $\mathrm{H}+$ than during $\mathrm{H}$ - in $\mathrm{P}-\mathrm{LB} \rightarrow \mathrm{HI}+$ trials.

Analysis of the topography of the response effect confirmed the acquisition of $\mathrm{H}+/ \mathrm{H}$ - discrimination and right-bar responding discrimination in MTS trials: right-bar responding was higher during gaps and reinforced targets than in

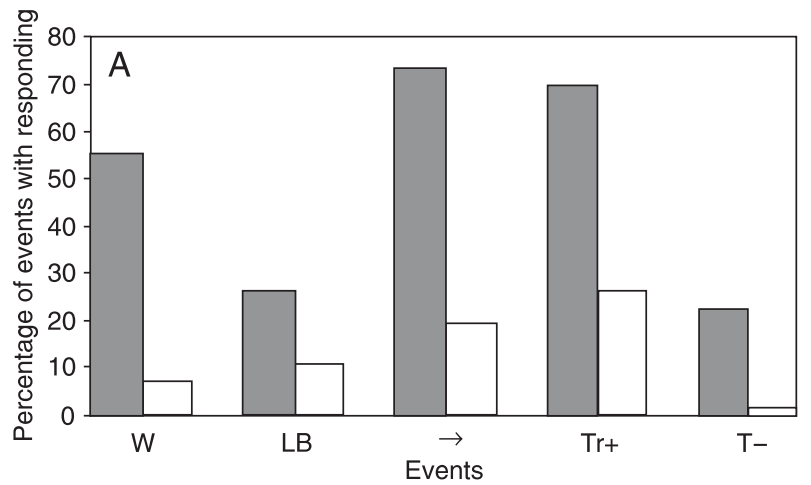

Right-bar responses target-alone trials (stimulus effect (ANOVA): $F(4,16)=$ 36.19047, $\mathrm{P}<0.01$ ) in both $\mathrm{P}-\mathrm{RB} \rightarrow \mathrm{Hr}+$ and $\mathrm{P}-\mathrm{LB} \rightarrow \mathrm{HI}+$ trials. As also observed in NMTS trials, there seemed to be the effect of an excitatory component for right-bar responding.

\section{Transfer tests}

Transfer tests 1 and 4 . Figure 3 shows the data for both transfer tests 1 and 4 , in which features used in NMTS training (W-LB and W-RB) preceded $\mathrm{H}$, used in MTS training. A statistically significant effect of stimulus (ANOVA) was observed for responding during trials $(F(11,44)=$ 9.768233, $\mathrm{P}<0.01$ ).

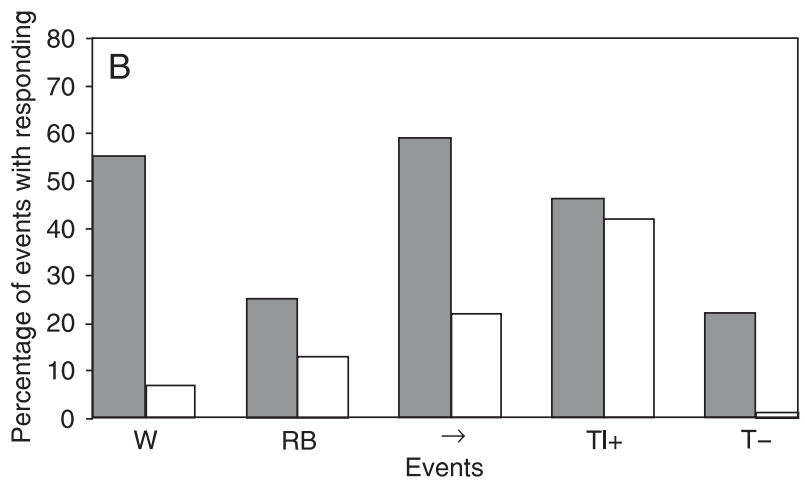

Left-bar responses

Figure 1. Percentage of events with responding during non-matching-to-sample (NMTS) stimulus conditional discrimination trials in the last 10 training sessions $(\mathrm{N}=5)$. $A$, Responding during $\mathrm{W}-\mathrm{LB} \rightarrow \mathrm{Tr}+$ and $\mathrm{T}$ - trials. $B$, Responding during $\mathrm{W}-\mathrm{RB} \rightarrow \mathrm{Tl}+$ and $\mathrm{T}-\mathrm{trials}$. $\mathrm{W}=5$-s white noise presentation; RB/LB = 5-s right/left bar light presentation; $\rightarrow=10$-s temporal gap; $\mathrm{T}=5$-s tone presentation; $\mathrm{r} / \mathrm{l}=$ right-left bar-pressing response; +/- = reinforcement/non-reinforcement.
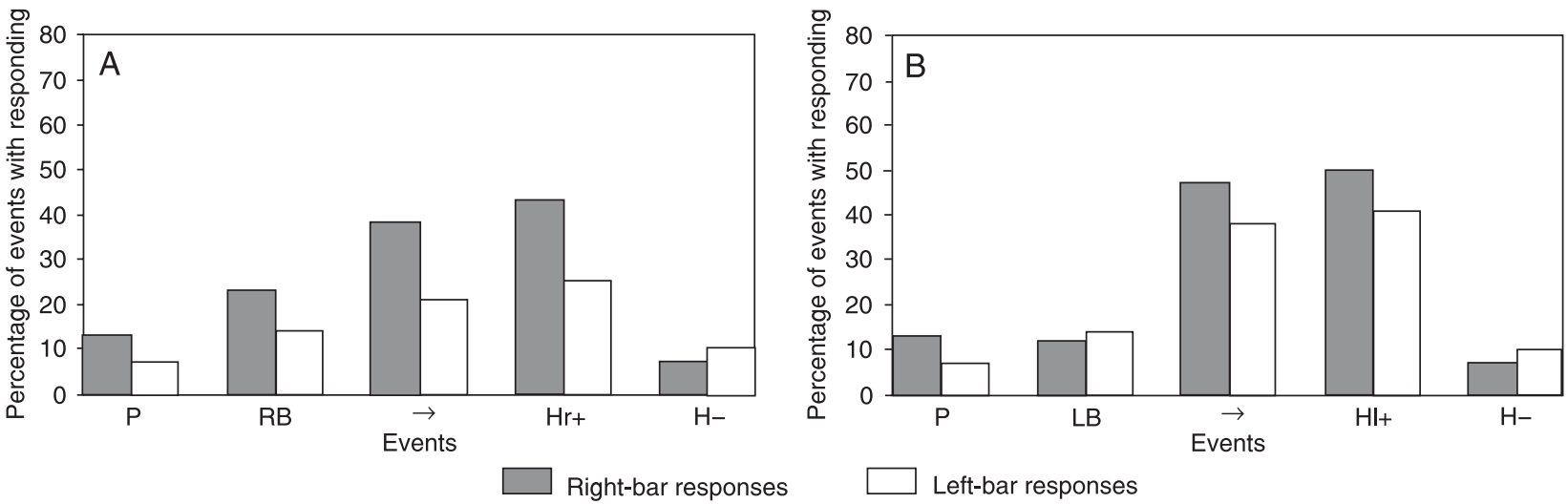

Figure 2. Percentage of events with responding during matching-to-sample (MTS) stimulus conditional discrimination trials in the last 10 training sessions $(\mathrm{N}=5)$. A, Responding during $\mathrm{P}-\mathrm{RB} \rightarrow \mathrm{Hr}+$ and $\mathrm{H}-$ trials. $B$, Responding during $\mathrm{P}-\mathrm{LB} \rightarrow \mathrm{HI}+$ and $\mathrm{H}-$ trials. $\mathrm{P}=5-\mathrm{s}$ panel light presentation; RB/LB = 5-s right/left bar light presentation; $\rightarrow=10$-s temporal gap; $H=5$-s house light presentation; $r / l=$ right-left bar-pressing response; +/- = reinforcement/non-reinforcement. 
Although stimulus effects were obtained for $\mathrm{W}-\mathrm{LB} \rightarrow \mathrm{H}-$ $(\mathrm{F}(6,24)=21.01873, \mathrm{P}<0.01$, ANOVA $)$, and $\mathrm{W}-\mathrm{RB} \rightarrow \mathrm{H}-$ $(F(6,24)=5.791271, P<0.01$, ANOVA $)$ trials, and $a$ response topography effect was obtained for $\mathrm{W}-\mathrm{RB} \rightarrow \mathrm{H}-$ $(F(1,6)=13.38562, P<0.02)$, post hoc comparisons did not show transfer effects, since responding did not differ statistically during targets preceded by composite features.

Transfer tests 2 and 3. Figure 4 shows the data for transfer tests 2 and 3 , in which the features used in MTS training ( $\mathrm{P}-\mathrm{RB}$ and $\mathrm{P}-\mathrm{LB})$ preceded $\mathrm{T}$, used in NMTS training. The stimulus effect was significant for responding during trials $(F(11,44)=6.943789, P<0.01$, ANOVA $)$, but not for response topography.

Although stimulus effects were obtained for responding during both $\mathrm{P}-\mathrm{RB} \rightarrow \mathrm{T}-$ and $\mathrm{P}-\mathrm{LB} \rightarrow \mathrm{T}$ - trials $(\mathrm{F}(6,24)=$ 6.995025, $P<0.01$ and $F(6,24)=9.942094, P<0.01$, respectively, ANOVA), no other statistically significant differential responding was observed that could indicate transfer.

Transfer test 5. Figure 5 shows the data for transfer test 5 , in which features used in both NMTS and MTS training preceded $\mathrm{C}$, a new stimulus which had not been applied in prior training. Statistical significance was obtained for response topography $(F(1,4)=11.57789, \mathrm{P}<0.03)$ and
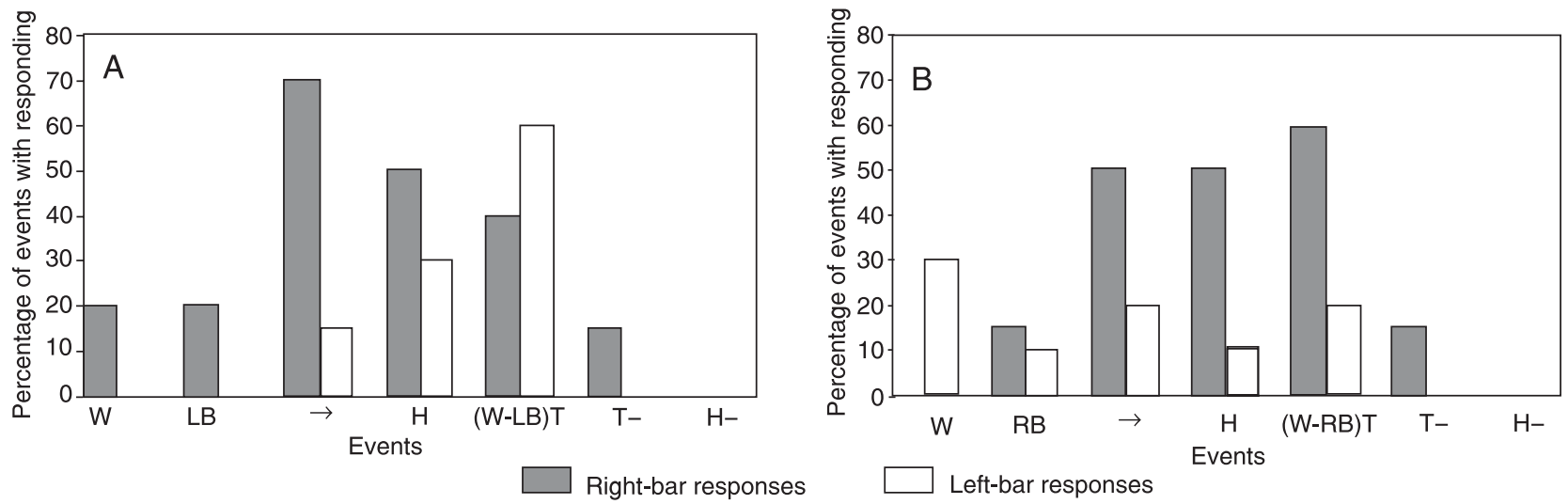

Figure 3. Percentage of events with responding during conditional discrimination trials in transfer tests 1 and $4(\mathrm{~N}=5)$. $A$, Responding during $\mathrm{W}-\mathrm{LB} \rightarrow \mathrm{H}-, \mathrm{T}$ (preceded by $\mathrm{W}-\mathrm{LB} \rightarrow$ ), and $\mathrm{T}-/ \mathrm{H}$ - target-alone trials. $B$, Responding during $\mathrm{W}-\mathrm{RB} \rightarrow \mathrm{H}-\mathrm{T}$ (preceded by W-RB $\rightarrow$ ), and $\mathrm{T}-/ \mathrm{H}$ - target-alone trials. $\mathrm{W}=5$-s white noise presentation; RB/LB $=5$-s right/left bar light presentation; $\rightarrow=10-\mathrm{s}$ temporal gap; $\mathrm{H}=5$-s house light presentation; $(\mathrm{W}-\mathrm{LB} / \mathrm{W}-\mathrm{LR}) \mathrm{T}=5$-s tone presentation, preceded by $\mathrm{W}$-LB $\rightarrow$ or $\mathrm{W}-\mathrm{RB} \rightarrow$; - = non-reinforcement.

Right-bar responses
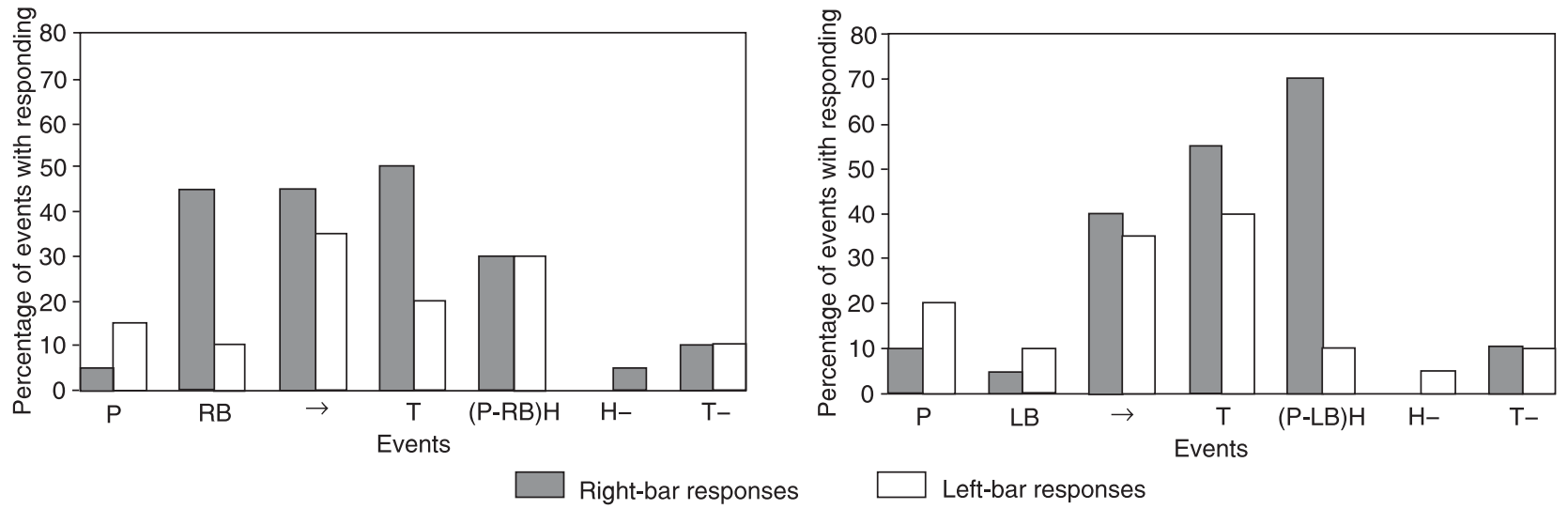

Figure 4. Percentage of events with responding during conditional discrimination trials in transfer tests 2 and $3(N=5)$. $A$, Responding during $\mathrm{P}-\mathrm{RB} \rightarrow \mathrm{T}-, \mathrm{H}$ (preceded by $\mathrm{P}-\mathrm{RB} \rightarrow$ ), and $\mathrm{H}-/ \mathrm{T}$ - target-alone trials. $B$, Responding during $\mathrm{P}-\mathrm{LB} \rightarrow \mathrm{T}-, \mathrm{H}$ (preceded by $\mathrm{P}-\mathrm{LB} \rightarrow$ ), and $\mathrm{H}-/ \mathrm{T}$ - target-alone trials. $\mathrm{P}=5$-s panel light presentation; RB/LB $=5$-s right/left bar light presentation; $\rightarrow=10-\mathrm{s}$ temporal gap; $T$ = 5-s tone presentation; $(\mathrm{P}-\mathrm{RB} / \mathrm{P}-\mathrm{LB}) \mathrm{H}=5$-s house light presentation, preceded by $\mathrm{P}-\mathrm{RB} \rightarrow$ or $\mathrm{P}-\mathrm{LB} \rightarrow$; $-=$ non-reinforcement. 
Figure 5. Percentage of events with responding during conditional discrimination trials in transfer test $5(\mathrm{~N}=5)$. Top, Responding during W-LB $\rightarrow$ C- (left panel), W-RB $\rightarrow$ C- (right panel) and $\mathrm{T}$ - target-alone trials. Bottom, Responding during $\mathrm{P}-\mathrm{RB} \rightarrow \mathrm{C}$ - (left panel), $\mathrm{P}-\mathrm{LB} \rightarrow \mathrm{C}-$ (right panel) and $\mathrm{H}$ - target-alone trials. $\mathrm{W}=5$ $\mathrm{s}$ white noise presentation; RB/LB $=5$-s right/ left bar light presentation; $\rightarrow=10$-s temporal gap; $\mathrm{P}=5$-s panel light presentation; $\mathrm{C}=5$-s clicker presentation; $\mathrm{T}=5$-s tone presentation; $\mathrm{H}=5$-s house light presentation; - = nonreinforcement.
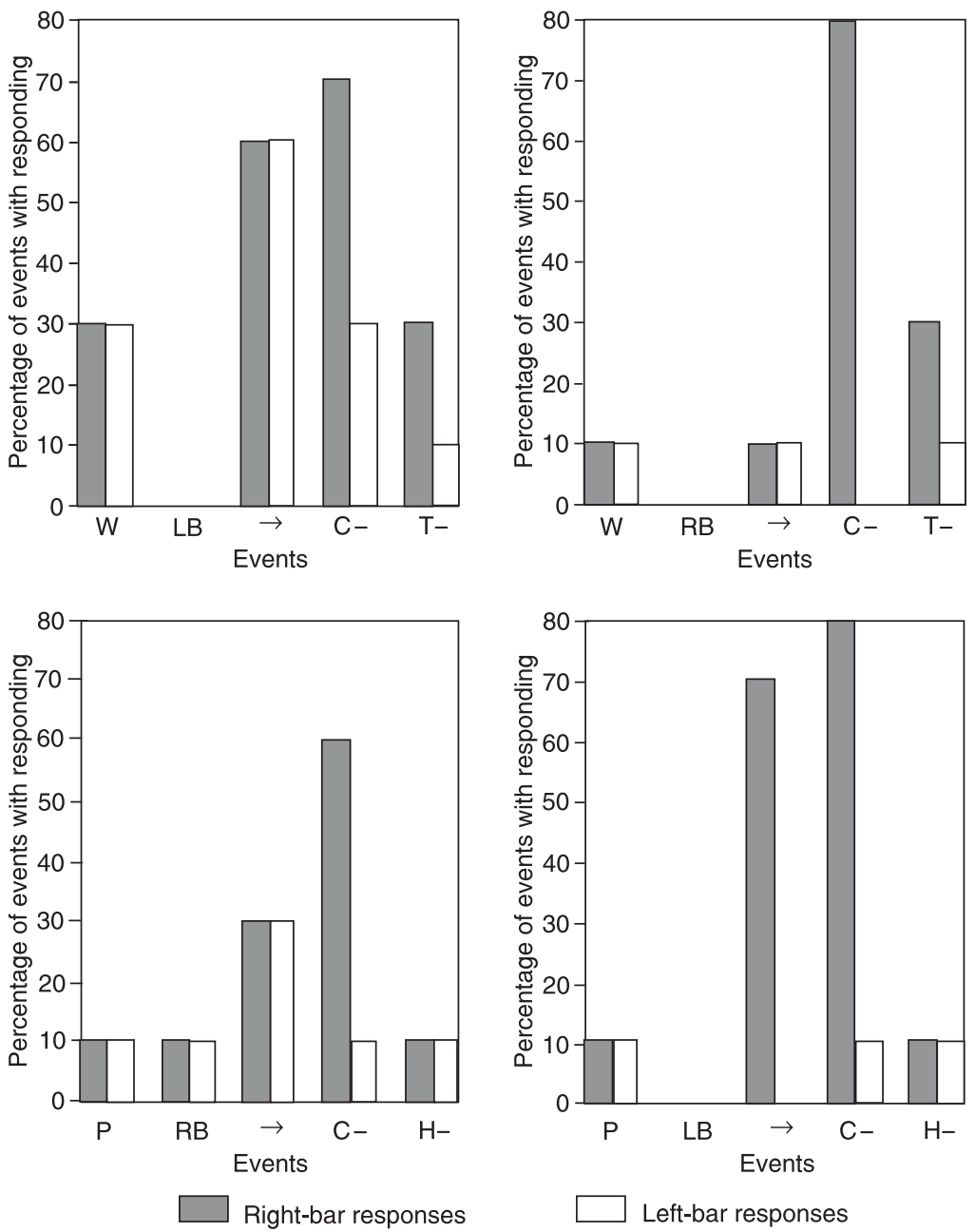

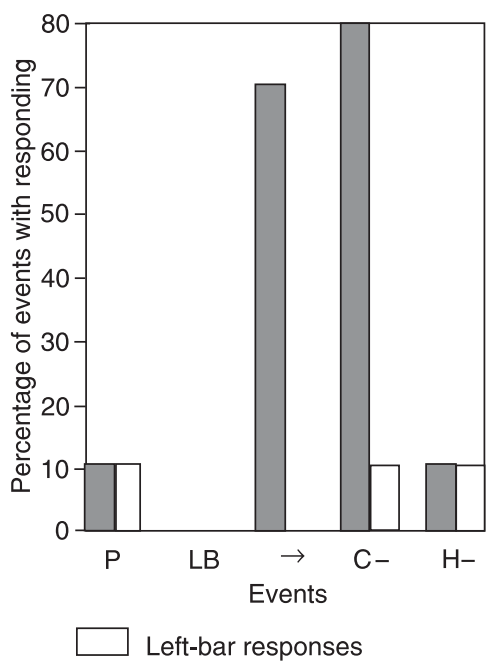

stimulus $(F(8,32)=14.40376, P<0.01)$. A significant interaction effect of response topography and stimulus was also obtained $(F(8,32)=3.443478, P<0.01)$.

Although a statistically significant stimulus effect was obtained for $\mathrm{W}$-LB $\rightarrow$ C- $(F(4,16)=8.647058, P<0.01)$, and effects of response topography $(F(1,4)=10.90566, P$ $<0.03)$ and stimulus $(F(4,16)=4.78049, P<0.01)$ were obtained for $\mathrm{W}-\mathrm{RB} \rightarrow \mathrm{C}-$, post hoc comparisons did not show transfer effects. In fact, responding during these trials only suggested the effect of a strong, excitatory association of right-bar responding during targets preceded by NMTS features since post hoc comparisons showed higher right- than left-bar responding during $C$ preceded by W-LB and W-RB.

Similar accounts can be made for responding during trials that used MTS features. During $\mathrm{P}-\mathrm{RB} \rightarrow \mathrm{C}-$ trials, although the figure suggests high right-bar responding during $C$, no statistical effects were obtained. During $\mathrm{P}$-LB $\rightarrow \mathrm{C}-$, ANOVA showed significant effects for response topography $(F(1,4)=10.59459, P<0.03)$, stimulus $(F(4,16)$ $=12.88889, \mathrm{P}<0.01)$ and response topography and stimulus interaction $(F(4,16)=13.67442, P<0.01)$. However, post hoc comparisons showed only higher right- than left-bar responding during $C$ preceded by $P-R B$ and $P-L B$.

\section{Discussion}

\section{Conditional discrimination training}

The present results suggest acquisition of conditional discrimination. Although there was responding in all cases, the data show differential responding during trials, that is, higher responding during target presentation in composite trials. Also, there was more responding during target presentation in composite than in single trials for both NMTS and MTS.

Discrimination of topography, that is, higher responding during reinforced topography in composite trials, would indicate acquisition of NMTS or MTS. The data show that 
such discrimination occurred only for reinforced right-bar responding in NMTS trials in which significant right-bar responding was observed during target presentation in $\mathrm{W}$ $\mathrm{LB} \rightarrow \mathrm{Tr}+$ composite trials. As the composite features had both conditional discrimination properties (related to the excitatory associations) and reinforced response topography ambiguity, it may have been harder to obtain full acquisition. Holland and Reeve (15) did not observe difficulties in acquisition, although trials with ambiguous features were presented to the subjects. Bueno and Moreira (16), however, did report such difficulty. Although there are differences between the study by Bueno and Moreira (16) and the present study, both can be considered procedures in which ambiguous targets were used, which made the procedure more complex, resulting in the incomplete acquisition observed, even with a high number of training sessions.

Besides the complexity of the procedure itself, properties of the stimuli can also account for the results observed. Both NMTS and MTS trials used features and targets of the same modality (in NMTS trials, $\mathrm{W}$ and $\mathrm{T}$ were auditory stimuli, and in MTS trials, all stimuli were visual). Schmajuk et al. (6) pointed out that such arrangement can make acquisition harder due to a generalization of stimulus properties that makes it more difficult to change the initial feature-unconditional stimulus excitatory associations to inhibitory ones. Also, auditory events are known to be more salient than visual ones for rats, making it easier to elicit more complex associations than simple conditioning ones (also discussed in Ref. 17). Nevertheless, the arrangement, although complex, produced learning, facilitating the acquisition of complex associations by the characteristics of the procedure itself, such as the temporal arrangement $(3,5,6,18)$, and the salience of stimuli, which may have facilitated acquisition of NMTS compared to MTS.

Besides the intrinsic properties of the stimuli or the arrangement, training itself produced representation of the stimuli and, especially, the relations among them. During the temporal gap, an increase of responding was found, as previously reported $(11,12)$, suggesting a prospective, occasion-setting strategy. This performance can also be discussed as the result of a configurational strategy (5), in terms of an association of the temporal gap and target as a configurational stimulus. In terms of the configurational hypothesis, an inhibitory output related to target units would have been masked by the excitatory properties of a temporal-gap/target unit activated by the presentation of a composite feature.

This discussion was also proposed by Caserta-Gon (11), supporting a configurational hypothesis to account for the data observed in her study as well as in the present experiment. However, Pearce (5) postulated in his model that a configuration is set between feature and target, which is different from what seems to have occurred in the present study. It should also be noted that most of the data supporting the configurational hypothesis resulted from simultaneous and not serial conditional discrimination procedures, as previously pointed out by Caserta-Gon (11). A configuration of the temporal gap and the target would imply considering more complex relations among the events in this procedure.

The implications of this argument support the hypothesis of Arnold et al. (9) when reporting higher order occasion setting. By using trials in which three stimuli were presented $(\mathrm{A} \rightarrow \mathrm{B} 1 \rightarrow \mathrm{L}+; \mathrm{B} 1 \rightarrow \mathrm{L}-; \mathrm{A} \rightarrow \mathrm{B} 2 \rightarrow \mathrm{L}-; \mathrm{B} 2 \rightarrow \mathrm{L}+)$, they observed third-order relations between events. This means that $L$ signaled the moment of reinforcement, but the excitatory or inhibitory properties of this target would be set by $\mathrm{B} 1$ or $\mathrm{B} 2$ presentations, which were first signaled by $\mathrm{A}$. According to these investigators, the temporal gaps inserted between stimuli could have favored the establishment of such relations, instead of less complex, configurational relations (the importance of temporal factors in providing more complex conditioning is also discussed by the authors mentioned above).

Although a configurational hypothesis seems to account for the results of the present study, the performance of subjects does not suggest a simple configuration, but third-order relations, in which the composite feature would inform the reinforcement schedule (W - NMTS; P - MTS) and the respective response topography (light bars) for the occasion of reinforcement (as suggested by the data, the configurational stimulus temporal gap/target). Such relations seem to have occurred only for the reinforced rightbar response in NMTS trials, considering the properties of this arrangement as discussed above.

However, if representations of both topographies occurred for this arrangement, allowing the occurrence of acquisition, even more complex representations might have been made. Such representations would concern not only the relation between the stimuli, but the representation of the two operant responses. Consequently, data must be discussed in terms of a more complex model. Schmajuk et al. (6), mostly based on Pavlovian procedure data, proposed a neural network approach, unifying both the configurational and occasion setting hypotheses. Shortterm memory traces would be responsible for activating output units of conditioned-unconditioned configurational stimuli (which refer to unitary representations of the events altogether), along with simple representations of each stimulus separately. As training occurs, excitatory and 
inhibitory associations would be set and discriminated, strengthening or weakening a certain CR-output unit. The strength of associations among input entries of conditioned configurational stimuli and output units of CR would account for the properties that a stimulus would acquire (simple conditioning or occasion setting).

According to this model, it is possible that the strength of the associations of the composite feature W-LB with the reinforcement allowed a configurational stimulus temporal-gap/T to acquire a strong excitatory component due to the temporal arrangement and the salience of the stimuli used in this trial. Since such relations occurred only for right-bar responding, the complexity of the procedure might have not allowed complete learning, favoring a generalization of right-bar responding in order to optimize performance during a complex task. So, even with an incomplete acquisition of response-topography discrimination, the performance suggests complex, third-order relations among the events and the simultaneous use of configurational strategies, supporting the neural network approach.

Also, the possibility of a primary association between feature and operant response cannot be ruled out, considering the tendency to increasing responding during the course of the trial. Nevertheless, it is relatively difficult to evaluate the relative contributions of the complex feature and the other elements of the compound trials to response control.

\section{Transfer tests}

In order to evaluate the nature of the representations acquired during training, responding during the transfer tests must be discussed. During tests 1 and 4 , features of NMTS preceded targets used in MTS training. Responding to $\mathrm{H}$ preceded by $\mathrm{W}$-LB and $\mathrm{W}$-RB suggests that the composite features kept their associations with $T$ at a certain level, although an effect of extinction seems to have masked any possible transfer, which indeed did not occur. No differential, statistically significant responding was observed, not even between responding during target in composite and single trials. This result contrasts with data observed during conditional discrimination training, where this differential responding was observed.

In addition, unexpected high right-bar responding was observed during $\mathrm{W}-\mathrm{RB} \rightarrow \mathrm{H}$ - trials, suggesting generalization of responding in this topography as a strategy to optimize performance in a too complex procedure. Thus, the incomplete acquisition of prior training might have been affected by the occurrence of different trials, favoring less complex associations, in this case, excitatory associations with right-bar responding during composite trials. On the other hand, the lack of transfer observed supports the hypothesis of the acquisition of complex representations of the stimuli during previous training.

Similar comments can be made for the data obtained in tests 2 and 3 . In these tests, MTS features preceded the targets used in NMTS trials. Although no statistically significant differential responding was found, high right-bar responding was observed during target presentation in all composite features, including $\mathrm{P}-\mathrm{LB} \rightarrow \mathrm{H}-$ and $\mathrm{P}-\mathrm{RB} \rightarrow \mathrm{T}-$ trials, where such data were not expected. On the one hand, a certain level of transfer of P-RB to $T$ can be suggested; however, the data of tests 1 and 4 support the hypothesis of effects of both extinction and generalization of right-bar responding. So, the separate excitatory components of both $\mathrm{P}-\mathrm{RB}$ and $\mathrm{T}$ (or a configurational stimulus temporal gap/T) might have strengthened the right-bar CR output since the complexity of the procedure might have favored simpler strategies. It must also be noted that incomplete topography acquisition was observed for MTS in prior training. Excitatory components of feature representations might have not acquired specific associations with $\mathrm{H}$. The sum of the excitatory components of the composite features and $\mathrm{T}$ (during which better performance, and thus, more complex representations were observed) can explain the data obtained in tests 2 and 3 . Thus, the effects of extinction reached the representations that were less established, that is, NMTS third-order relations and the incomplete acquisition of MTS.

The lack of transfer between NMTS and MTS supports the data reported by Bueno and Croisfelts (12), who also did not observe transfer between feature-positive conditional discriminations. However, statements based on these data should be considered with caution given the number of subjects and incomplete acquisition observed both in the study by Bueno and Croisfelts (12) and in the present study. Nevertheless, the data observed contrast with the neural network approach proposed by Schmajuk et al. (6), which postulates that transfer between occasion setters occurs more easily than in response to a new stimulus.

The implications of this argument must also consider the data of test 5 , in which a new auditory stimulus was presented after the composite features. An overview of the data shows no transfer of the original properties of the composite features to $\mathrm{C}$. In addition, there was unexpected higher right-bar responding during trials in which left-bar responding was more likely to occur. Right-bar responding during $\mathrm{C}$ in $\mathrm{W}-\mathrm{RB} \rightarrow \mathrm{C}$ - and $\mathrm{P}$-LB $\rightarrow \mathrm{C}$ - trials was differential for topography in the former and when compared with $T$ and $\mathrm{H}$ - presentations for both composite trials. It should be observed that extinction seriously affected left-bar responding, indicating a right-bar responding optimization strategy. 
The procedure adopted was very complex, but allowed a certain acquisition. The data suggest that rats can acquire complex tasks if contingencies are handled better in order to allow increasingly complex information processing. Thus, other experiments should be designed in order to test previous preparation that could facilitate such training.

The lack of transfer for stimuli that were part of other conditional discriminations contrasts with the neural network approach (6), as pointed out above. The lack of transfer to a new stimulus, however, supports this model, in contrast to the study by Caserta-Gon (11), who observed transfer to a new stimulus using both featurepositive and-negative discriminations. Bueno and Croisfelts (12) observed a similar effect of transfer, although more diffuse in terms of topography responding. The hypothesis that arises from the data of the present study indicates some questions which could not have been well discussed

\section{References}

1. Jenkins HM, Sainsbury RS. The development of stimulus control through differential reinforcement. In: Mackintosh NJ, Honig WK (Editors), Fundamental issues in associative learning. Hallifax: Dalhousie University Press; 1969.

2. Rescorla RA. Inhibition and facilitation. In: Miller RR, Spear $\mathrm{NE}$ (Editors), Information processing in animals: Conditioned inhibition. Hillsdale: Erlbaum; 1985. p 299-326.

3. Holland PC. Occasion setting in Pavlovian conditioning. In: Medin DL (Editor), The psychology of learning and motivation. Vol. 28. New York: Academic Press; 1992. p 69-125.

4. Ross RT, Holland PC. Conditioning of simultaneous and serial feature positive discriminations. Anim Learn Behav 1981; 9: 139-303.

5. Pearce JM. Similarity and discrimination: a selective review and a connectionist model. Psychol Rev 1994; 101: 587607.

6. Schmajuk NA, Lamoureux JA, Holland PC. Occasion setting: a neural network approach. Psychol Rev 1998; 105: 332.

7. Colwill RM, Rescorla RA. Evidence for the hierarchical structure of instrumental learning. Anim Learn Behav 1990; 18: 71-82.

8. Holland PC. Transfer of occasion setting across stimulus and response in operant serial feature-positive discriminations. Learn Motiv 1995; 26: 239-263.

9. Arnold HM, Grahame NJ, Miller RR. Higher order occasion setting. Anim Learn Behav 1991; 19: 58-64.

10. Goddard MJ, Holland PC. Type of feature affects transfer in due to the data obtained. Would different modalities of stimuli have favored NMTS over MTS acquisition? How accurate was responding during the transfer tests? The use of more subjects, counterbalancing groups and better prior training to the conditional discrimination should be considered in order to test the hypothesis proposed in the present study. Both Caserta-Gon (11) and Bueno and Croisfelts (12) have used procedures involving different topography operant responses; however, the use of a similar, although more complex procedure is relatively new in the literature (compare with Ref. 9). Thus, the complexity of this procedure can be a way to test variables that could soften the theories about conditional discrimination learning, especially the neural network approach, which does not offer a discussion about other schedules presented at the same time as in the classical conditional discrimination design (in the present study, NMTS and MTS). operant serial feature-positive discriminations. Anim Learn Behav 1996; 24: 266-276.

11. Caserta-Gon MC. Respostas de rotação como índice de associações em procedimentos de discriminação condicional. [Master's thesis]: Faculdade de Filosofia, Ciências e Letras de Ribeirão Preto, USP; 1994.

12. Bueno JLO, Croisfelts $\mathrm{H}$. Efeito de diferentes modalidades de estímulos em procedimentos de discriminação condicional. V Congresso Interno do Núcleo de Pesquisa em Neurociências e Comportamento. 1995. p 120 (Abstract).

13. Homem AJM. Interface para controles externos de caixas de experimentos de ratos via computador. $V$ Congresso Interno do Núcleo de Pesquisa em Neurociências e Comportamento. 1995. p 128 (Abstract).

14. Donzelli CAF, Croisfelts H, Bueno JLO. Programa CONTEXP para controle experimental de pesquisa em comportamento animal. Psicol Teoria Pesq 1998; 14: 267-269.

15. Holland PC, Reeve CE. Acquisition and transfer of control by an ambiguous cue. Anim Learn Behav 1991; 19: 113124.

16. Bueno JLO, Moreira RCM. Conditional discrimination: the role of CS-alone trials. Behav Processes 1998; 42: 33-45.

17. Holland PC. Occasion setting with simultaneous compounds in rats. J Exp Psychol Anim Behav Process 1989; 15: 183193.

18. Holland PC, Hamlin PA, Parsons JP. Temporal specificity in serial feature-positive discrimination learning. J Exp Psychol Anim Behav Process 1997; 23: 95-109. 